\title{
Impactos de Ações Judiciais na Preservação de Vidas Negras nas Favelas: ACP da Maré e ADPF das FaVelas ${ }^{1,2}$
}

\author{
Daniel Hirata ${ }^{3}$ \\ Shyrlei Rosendo dos Santos ${ }^{4}$ \\ Carolina Christoph Grillo ${ }^{5}$ \\ Camila Barros Moraes ${ }^{6}$ \\ Renato Dirk $^{7}$ \\ Lidiane Malanquini ${ }^{8}$
}

\section{INTRODUÇÃO}

Em 6 de maio de 2019, a Coordenadoria de Recursos Especiais (CORE) da Polícia Civil realizou uma operação policial no Conjunto Esperança, situado no Conjunto de Favelas da Maré, na Zona Norte da cidade do Rio de Janeiro. Segundo a Assessoria de Imprensa da Polícia Civil, o objetivo da operação era capturar um dos responsáveis por confrontos entre facçôes em São Gonçalo, município da região metropolitana do Rio de Janeiro, que estaria escondido na Maré. Auxiliados por um helicóptero e dois carros blindados, policiais perseguiram a pé oito jovens negros, encurralando-os em uma rua. De acordo com relatos de moradores, quatro desses jovens entraram na casa de uma família em busca de abrigo. Dois deles subiram para o terceiro andar, enquanto os demais permaneceram no térreo. Estes se renderam, com as mãos ao alto e armas ao solo, logo que os policiais entraram na casa, mas ainda assim foram executados diante dos moradores. Em seguida, os agentes se dirigiram ao terceiro andar, onde executaram os outros dois jovens, e arrastaram seus corpos até a saída da casa, utilizando os lençóis dos moradores. "A ordem é matar", teriam dito os policiais, antes de colocarem os corpos dos quatro jovens no carro blindado e seguirem com a operação policial. No interior da casa, foram encontradas dezoito cápsulas de munição, móveis e eletrodomésticos alvejados, roupas jogadas no chão, muito sangue e marcas de tiros nas paredes e janelas. Duas crianças e uma adolescente presenciaram o ocorrido. Nessa mesma operação e na mesma rua, foram registradas as mortes de outros quatro jovens. Em apenas um dia, em uma única rua, oito jovens, todos identificados como pretos ou pardos, foram sumariamente executados.

Os relatos de moradores em que se baseou a reconstituição descrita instruíram a Ação Civil Pública (ACP) da Maré, movida desde 2016 pelo Núcleo de Defesa dos Direitos Humanos (NUDEDH) e pelo Núcleo Contra a Desigualdade Racial (Nucora) da Defensoria Pública do Estado do Rio de Janeiro. A operaçáo policial em questáo foi acusada de violar a liminar concedida em

1. DOI: http://dx.doi.org/10.38116/bapi26art2

2. As pesquisas aqui referidas contaram com o apoio de projetos financiados pelo Conselho Nacional de Desenvolvimento Científico e Tecnológico (CNPq), da Fundação de Amparo à Pesquisa do Estado do Rio de Janeiro (FAPERJ) e da Fundação Heinrich Böll. Agradecemos aos pareceristas, à equipe de revisão e aos editores pelas valiosas contribuições para este artigo.

3. Professor de sociologia na Universidade Federal Fluminense (UFF) e coordenador do Grupo de Estudos dos Novos llegalismos (GENI)/UFF.

4. Pesquisadora da Redes de Desenvolvimento da Maré.

5. Pós-doutoranda do Programa de Pós-Graduação em Sociologia (PPGS)/UFF e coordenadora do GENI/UFF.

6. Pesquisadora da Redes de Desenvolvimento da Maré.

7. Estatístico e pesquisador do GENI/UFF.

8. Pesquisadora da Redes de Desenvolvimento da Maré. 
2017, no âmbito dessa ACP, que fixava um protocolo para as operaçóes policiais na Maré. Não se trata, contudo, de um caso excepcional. Pelo contrário, a narrativa que abre este trabalho é exemplar da violência que caracteriza as operaçóes policiais no estado do Rio de Janeiro e que, recentemente, no contexto da pandemia da Covid-19, foi objeto de outra liminar, concedida pelo Supremo Tribunal Federal (STF). No âmbito da Arguição de Descumprimento de Preceito Fundamental (ADPF) no ${ }^{\circ}$ 635, o STF restringiu as operaçóes policiais em favelas durante a pandemia. Os efeitos de violência dessas operaçóes afetam especialmente a interseção populacional de raça, classe social, pertencimento territorial e perfil etário em que se situavam aqueles oito jovens negros moradores de favelas, sumariamente executados sob "ordem para matar".

Segundo Almeida (2018, p. 16), o racismo é estrutural no Brasil, pois "fornece o sentido, a lógica e a tecnologia para as formas de desigualdade e violência que moldam a vida social contemporânea". No que tange particularmente à violência, é preciso destacar que a taxa de homicídios para negros entre 19 e 24 anos é quase sete vezes maior que a taxa geral da populaçáo brasileira, atingindo duzentos a cada 100 mil habitantes (Ramos et al., 2020). No Brasil, para cada indivíduo náo negro assassinado encontramos 2,4 negros mortos, e, no Rio de Janeiro, a chance de um indivíduo negro ser assassinado é 23,4\% maior que a dos náo negros, sendo que, para todo o decil com maior chance de morrer, 78,9\% são negros (Cerqueira e Coelho, 2017). Parte significante dessas mortes decorre de açóes policiais, pois, compondo $55 \%$ da população brasileira, os negros representam 75,4\% das vítimas da letalidade policial (FBSP, 2019). Para o caso do Rio de Janeiro, o estado que concentra o maior número de mortes decorrentes de açóes policiais no Brasil (Ramos et al., 2020), as circunstâncias dessa letalidade estão associadas fortemente às operaçóes policiais de incursão armada em favelas (Monteiro, Fagundes e Guerra, 2020). São elas o principal instrumento da ação pública (Lascoumes e Le Galès, 2004) para o controle da criminalidade violenta no estado. Há mais de três décadas, as operaçóes policiais são o método preferencial de direcionamento do uso da força por parte do governo do estado do Rio de Janeiro e de emprego dos seus recursos financeiros, tecnológicos e humanos (Hirata e Grillo, 2019). Das mortes decorrentes de operaçóes policiais nas favelas da Maré, 93,3\% das vítimas com dados raciais informados são negras (Redes de Desenvolvimento da Maré, 2017; 2018; 2019; 2020).

Este texto resulta da colaboração entre o Grupo de Estudos dos Novos Ilegalismos da Universidade Federal Fluminense (GENI/UFF) e a Redes de Desenvolvimento da Maré, que visa examinar os impactos de preservação da vida de duas experiências de açóes jurídicas informadas pela produção de dados sobre operaçóes policiais a partir da sociedade civil. Sáo elas: i) a ACP da Maré, protocolada no Tribunal de Justiça do Rio de Janeiro em junho de 2016 sob o Processo n⿳o 0215700-68.2016.8.19.0001; e ii) a ADPF no 635 - a ADPF das Favelas -, protocolada no STF em novembro de 2019 pelo Partido Socialista Brasileiro. Procuraremos mostrar que as decisóes judiciais que visam estabelecer limites legais para as operaçóes policiais produziram impactos muito significativos de redução da violência delas decorrente, sem que houvesse aumento das ocorrências criminais.

\section{OPERAÇÕES POLICIAIS E AÇÕES JUDICIAIS: A QUANTIFICAÇÃO DOS IMPACTOS}

Não existem dados oficiais sobre operações policiais. Logo, a construção de formas de quantificação é feita por meio da mobilização da sociedade civil ou do chamado statactivisme ${ }^{9}$ (Bruno, Didier e

9. 0 neologismo statactivisme, em francês, é um conceito que pretende dar conta das possibilidades de incidência da estatística e, de forma mais geral, dos números, nos campos universitário, social e artístico. Nos alinhamos particularmente a uma das formas de existência do statactivisme, qual seja a produção de dados alternativos que redefinem ações no espaço público. 
Prévieux, 2014). Dentro de um contexto emergente da produção de dados sobre operaçóes policiais nos últimos anos, a Redes de Desenvolvimento da Maré, por meio do Eixo de Direito à Segurança Pública e Acesso à Justiça, foi pioneira. Os levantamentos in loco realizados desde 2016 por esta instituição da sociedade civil, no Conjunto de Favelas da Maré, são os de melhor qualidade disponíveis até hoje, não apenas por compilarem dados de fontes secundárias mas também por produzirem dados a partir da atuação de agentes em campo, muitos deles moradores da Maré, e de sua extensa rede de colaboradores (mais de 140 pessoas em 21 organizaçóes). Os dados coletados e transformados em números são divulgados por meio da publicação de um boletim anual que atualiza, entre outras informaçóes, dados sobre as operaçóes policiais na Maré. A cada ano, esse boletim vai avançando em novos elementos analíticos que ajudam a compreender os impactos das operaçóes policiais, por exemplo, o número de dias sem aulas. ${ }^{10}$

Em seguida, o Centro de Estudos de Segurança e Cidadania (CESeC), ${ }^{11}$ referência na política de dados alternativos no Brasil, produziu relatórios importantes durante a intervenção federal em 2018 e, agora no formato da Rede de Observatórios da Segurança, monitora continuamente por meio de mídia impressa e redes sociais a atividade policial, quantificando açóes de patrulhamento e operaçóes. O laboratório de dados Fogo Cruzado, ${ }^{12}$ por sua vez, destaca-se por produzir dados sobre a incidência de tiroteios, desde 2016, também tendo como fonte a imprensa e as redes sociais. Apesar de não produzir dados específicos sobre operaçóes policiais, o Fogo Cruzado realiza a contagem de tiroteios com presença de agentes de estado, possibilitando uma aproximação com os eventos típicos das operaçóes policiais.

Desde 2018, o GENI/UFF vem realizando um grande levantamento de dados em ampla série histórica (com início em 1989 e alimentação contínua da base) e abrangência geográfica para toda a região metropolitana do Rio de Janeiro. Os elementos descritivos mais gerais utilizados para a caracterização das operaçôes policiais são a sua evolução temporal, as instituiçóes oficiais que delas participaram, sua localização e seus impactos, ou seja, cabe entender quantas operaçôes foram feitas ao longo da série histórica, quem foi o responsável, onde a operação foi realizada e quais os seus impactos ou resultados (mortos, feridos, prisóes e apreensóes). Como complemento importante a essas questóes, sempre que possível acrescenta-se a variável motivação, ou seja, por qual razão essas operações foram realizadas (Hirata e Grillo, 2019).

Os boletins divulgados pela Redes de Desenvolvimento da Maré permitiram avaliar os impactos de redução de violência da ACP da Maré. Na ocasião de sua construçáo, foram promovidas várias reuniốes de escuta da população, por meio das quais foi possível elaborar as principais demandas acerca das operaçóes policiais. Um ano depois, em junho de 2017, foi concedida, pelo Tribunal de Justiça do Estado do Rio de Janeiro, uma decisão liminar que determinou uma série de medidas restritivas para que as operaçóes policiais ocorressem na Maré, como a proibição de operaçóes para cumprimento de mandados judiciais durante a noite, a instalação gradual de câmaras de vídeo, aparelhos de áudio e sistema de posicionamento global (global positioning system - GPS) nas viaturas, a disponibilização de ambulâncias em dias de operaçóes policiais e a elaboração de um plano de redução de danos.

10. Mais informaç̧ões disponíveis em: <https://www.redesdamare.org.br/br/eixos/3/direito-a-seguranca-publica-e-acesso-a-justica> .

11. Disponível em: <https://cesecseguranca.com.br>.

12. Disponivel em: <https://fogocruzado.org.br>. 
Em 2018, enquanto os números de violência de todo o estado do Rio de Janeiro aumentaram, os da Maré diminuíram. Conforme o Boletim Direito à Segurança Pública na Maré no 3 (Redes de Desenvolvimento da Maré, 2019), houve uma redução no volume de operaçôes policiais entre 2017 e 2018, o que resultou em menos dias sem aula e sem atendimento nos postos de saúde e menos confrontos armados, mortos e feridos. Quando comparados os anos de 2017 e 2018, percebeu-se uma redução de $61 \%$ nas operaçóes policiais, de $43 \%$ nos confrontos entre os grupos armados, de $71 \%$ dos dias sem aula e de $76 \%$ dos dias sem atendimento nos postos de saúde. Em julho de 2019, atendendo à solicitação do governador Wilson Witzel, uma juíza decidiu pela suspensão dos efeitos da ACP da Maré, restabelecidos um mês depois pelo desembargador Jessé Torres. A tabela 1 apresenta os dados anuais do monitoramento realizado na Maré.

\section{TABELA 1}

Maré: número de operações policiais, mortos e feridos e quantidade de dias sem aula e sem atividades nas unidades de saúde (2016-2019)

\begin{tabular}{lccccc}
\hline Ano & Operações & Mortos & Feridos & Dias sem aula & Dias sem atividades nas unidades de saúde \\
\hline 2016 & 33 & 17 & 8 & 28 & 20 \\
2017 & 41 & 20 & 41 & 27 & 36 \\
2018 & 16 & 19 & 13 & 10 & 11 \\
2019 & 39 & 34 & 30 & 24 & 25 \\
Total & $\mathbf{1 2 9}$ & $\mathbf{9 0}$ & $\mathbf{9 2}$ & $\mathbf{8 9}$ & $\mathbf{9 2}$ \\
\hline
\end{tabular}

Fonte: Redes de Desenvolvimento da Maré.

O ano de 2018, o único em que a vigência da liminar que restringia operaçóes durou o ano inteiro, foi aquele em que ocorreu um aumento nas operaçôes policiais na região metropolitana do Rio de Janeiro, sendo que, como se pode notar, neste mesmo ano foi constatado o menor número de operações (e seus impactos) na Maré, sugerindo fortemente a efetividade da liminar. Já em 2019, primeiro ano do governo Witzel e o ano em que houve suspensão da liminar, as operaçôes aumentaram significativamente tanto na Maré como na região metropolitana do Rio de Janeiro. Consequentemente, o número de feridos por arma de fogo subiu de 13 para 30, os dias sem aula e sem atividades nas unidades de saúde aumentaram de 10 para 24 e de 11 para 25 dias, respectivamente, e o número de mortos em decorrência das operaçóes teve um aumento de 79\%, de 19, em 2018, para 34, em 2019. Cabe ressaltar que todos os mortos em operaçóes policiais em 2019 foram identificados como pretos e pardos. Assim que a liminar foi restabelecida, em agosto de 2019, pôde-se observar mais uma vez uma redução dos efeitos de violência e de interrupção dos serviços de educação e saúde na Maré.

Na esteira da ACP da Maré, a ADPF no 635 foi requerida a fim de frear a "excessiva e crescente letalidade da atuação policial, voltada sobretudo contra a população pobre e negra de comunidades". ${ }^{13}$ São exigidas providências como a formulação de um plano para a redução das mortes decorrentes de açóes policiais, protocolos claros para a realização de operaçôes, a proibição de disparos de tiro nas imediaçóes de creches, escolas e equipamentos de saúde e maior accountability e transparência de dados. Como amici curiae da ADPF n⿳o 635, participam diversos movimentos, instituiçóes e/ou organizaçóes

13. Disponível em: <https://bit.ly/3tPqelT>. 
da sociedade civil. Pela primeira vez na história do Brasil, movimentos de favela submeteram a sua própria sustentaçáo oral ao STF em um julgamento sobre o tema da segurança pública. ${ }^{14}$

Quando os efeitos da pandemia da Covid-19 se fizeram sentir no Brasil, a votação da ADPF no plenário do STF foi suspensa. Contudo, no dia 5 de junho, o relator do processo, o ministro Edson Fachin, emitiu decisão liminar proibindo as operaçóes policiais durante a pandemia, salvo em casos "absolutamente excepcionais". Esta decisão foi mantida por nove votos a dois na votação em tribunal pleno. O GENI/UFF produziu um relatório técnico (Hirata, Grillo e Dirk, 2020) que foi anexado aos autos, visando à instruçáo do julgamento da $\operatorname{ADPF} \mathrm{n}^{-}$635. A pesquisa utilizou dados oficiais sobre ocorrências criminais produzidos pelo Instituto de Segurança Pública (ISP), dados próprios sobre operaçóes policiais e dados sobre tiroteios do Fogo Cruzado. O relatório questionava a presunçáo de que as operaçóes policiais seriam um meio eficaz e incontornável de controle do crime no contexto particularmente violento do Rio de Janeiro. Os testes de correlaçáo entre operaçóes policiais e ocorrências criminais registradas no período de 2007 a 2019 apontaram que o aumento das primeiras náo é acompanhado da diminuição das segundas, mas, sim, o seu inverso: um maior número de operaçóes policiais associa-se a um aumento dos crimes contra a vida $(\rho=0,61)$, particularmente os homicídios dolosos $(\rho=0,71)$, e náo impacta significativamente a redução dos crimes contra o patrimônio $(\rho=0,40)$, inclusive aumentando certos tipos, como é o caso do roubo a veículos $(\rho=0,61) .{ }^{15}$

Os gráficos de dispersão a seguir (gráficos 1 e 2) mostram como se distribui essa associação, representando a variação percentual anual do número de operaçóes policiais e de ocorrências de crimes contra a vida, bem como a força da correlaçáo entre essas variáveis. O eixo vertical refere-se à variação percentual anual do número de crimes contra a vida, ao passo que o eixo horizontal se refere à variação percentual anual do número de operaçóes policiais, o que oferece as combinaçóes de cada quadrante. $\mathrm{O}$ rótulo de dados em cada ponto do gráfico designa o ano a que o ponto se refere na série entre 2007 e 2019 , por exemplo, o ponto rotulado como 17 representa a variaçáo percentual entre 2016 e 2017. A localização de cada ponto no gráfico corresponde ao valor da diferença percentual do número de operaçôes policiais e de vítimas de crimes contra a vida em cada um desses anos em relação ao ano anterior. Por exemplo, a localização do ponto rotulado como 17 no gráfico refere-se à diferença percentual entre 2016 e 2017, do número de operaçóes (eixo horizontal) e do número de vítimas de crimes contra a vida (eixo vertical). Já o tamanho do ponto expressa o número de operaçóes do ano que o rótulo de dados designa, por exemplo, o tamanho do ponto que representa a diferença entre 2016 e 2017, ponto 17, corresponde ao número de operaçóes em 2017.

\footnotetext{
14. As entidades habilitadas como amicus curiae foram: Educação e Cidadania de Afrodescendentes e Carentes (Educafro), Defensoria Pública do Estado do Rio de Janeiro, Justiça Global, Redes de Desenvolvimento da Maré, Movimento Negro Unificado, Instituto de Estudos da Religião (ISER), Conselho Nacional dos Direitos Humanos (CNDH), município de Angra dos Reis, Coletivo Papo Reto, movimento Mães de Manguinhos, Rede de Comunidades e Movimentos contra a Violência, Fala Akari e Iniciativa Direito à Memória e Justiça Racial.

15. Essa parte do trabalho corrobora o estudo de Monteiro, Fagundes e Guerra (2020), que usa a letalidade policial como proxy das operações policiais.
} 


\section{GRÁFICO 1}

Região metropolitana do Rio de Janeiro: correlação entre operações policiais e crimes contra a vida (2007-2019)

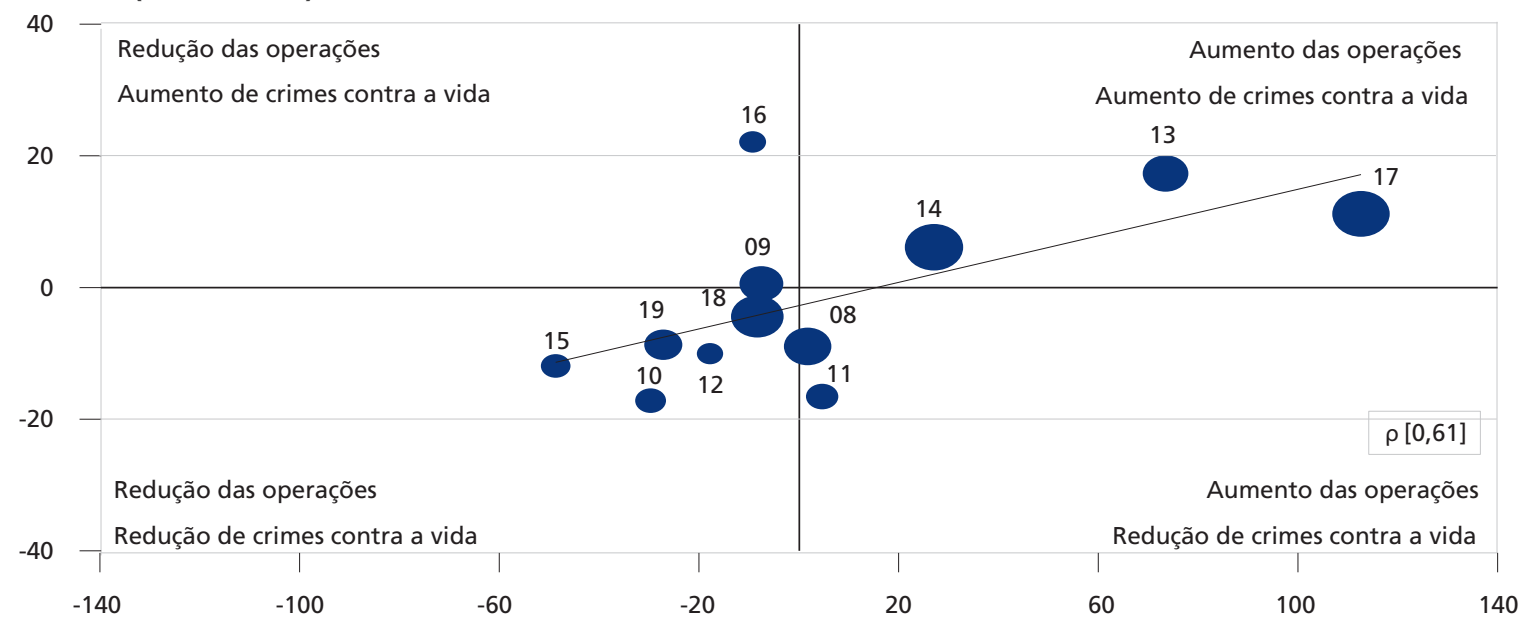

Fonte: ISP e GENI/UFF.

Elaboração: GENI/UFF.

Obs.: Dispersão feita pelas diferenças percentuais anuais de 2007 a 2019.

\section{GRÁFICO 2}

Região metropolitana do Rio de Janeiro: correlação entre operações policiais e crimes contra o patrimônio (2007-2019)

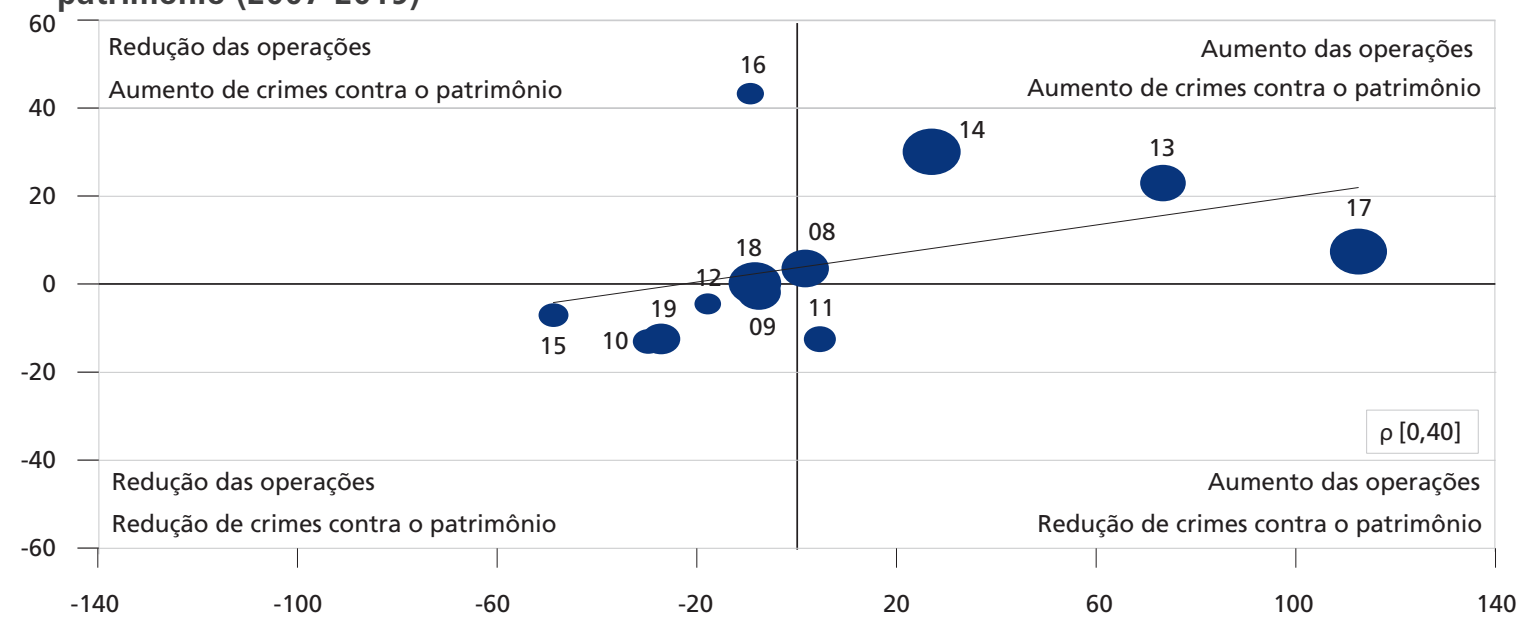

Fonte: ISP e GENI/UFF.

Elaboração: GENI/UFF.

Obs.: Dispersão feita pelas diferenças percentuais anuais de 2007 a 2019.

Nesse mesmo relatório produzido pelo GENI/UFF, compararam-se os 31 primeiros dias de vigência da liminar do ministro Fachin com a média do mesmo período nos últimos treze anos e constatou-se a redução do número de feridos (49,6\%) e de mortos (72,5\% entre policiais e civis) decorrente dessas operaçóes. Tais impactos não produziram um aumento das ocorrências criminais, mas, sim, a sua diminuição: houve redução de 47,7\% nos crimes contra a vida e, particularmente nos casos de homicídios dolosos, diminuição de 39,9\%, além de redução de 39,0\% nos crimes contra o patrimônio, em particular de $32,1 \%$ nos casos de roubo de veículos. Em que se pese os efeitos da pandemia no período considerado, em seu conjunto os dados indicaram, portanto, a ineficiência das 
operaçóes policiais no controle do crime e a efetividade do deferimento do pedido de tutela provisória incidental na ADPF no 635 em preservar vidas. O estudo afirmava que a postura de negligenciar a defesa da vida sob a justificativa de uma suposta efetividade no controle da criminalidade violenta não era corroborada por uma análise assentada em dados.

Os números do monitoramento da violência armada da Redes de Desenvolvimento da Maré também sofreram um impacto significativo após a liminar do ministro Edson Fachin. Ao comparar os meses de junho e julho de 2019 e 2020, percebeu-se que em junho de 2020, após a liminar, o número de operaçóes policiais caiu 75\%, resultando na diminuição de cinco mortes, em junho de 2019, para nenhuma, em junho de 2020. Em julho de 2020, o impacto foi ainda maior, não havendo nenhuma operação e nenhuma morte no período, em contraste com as cinco operaçóes policiais realizadas no mesmo mês em 2019 e as seis mortes delas decorrentes. A partir dessas comparaçóes, é possível estimar que a liminar que restringiu as operaçóes policiais no período de pandemia da Covid-19 contribuiu para salvar onze vidas de moradores da Maré.

\section{CONSIDERAÇÕES FINAIS}

Este artigo visou demonstrar os impactos de redução da violência e preservação da vida, sobretudo de jovens negros, produzidos pela construção de mecanismos de garantia de direitos coletivos e individuais dos moradores de favela. Essas medidas não têm sido pensadas como parte das políticas de segurança pública no estado do Rio de Janeiro, contudo, as ações judiciais da ACP da Maré e da ADPF das Favelas têm obtido êxito em impor ao estado maior zelo com a preservaçáo da vida e das rotinas dos moradores de favelas sem consequente aumento das ocorrências criminais. Essas açóes contribuíram para diminuir o número de mortos e feridos, garantir o funcionamento dos serviços de educação e saúde, além de reduzir os crimes contra a vida e contra o patrimônio. Esses são indicativos de que o respeito às garantias individuais e coletivas e, principalmente, ao direito à vida não é contrário ao controle do crime. Faz-se, portanto, necessário que as políticas de segurança pública atuem com planejamento, inteligência, transparência, prestação de contas e em constante diálogo com a sociedade civil.

Como apontamento para futuras investigaçóes, cabe destacar que os perfis das operaçóes policiais na Maré, depois da vigência da ACP, e na regiâo metropolitana do Rio de Janeiro, depois da $\mathrm{ADPF} \mathrm{n}^{\circ}$ 635, passaram a apresentar características específicas: presença predominante de batalhóes e delegacias especializadas - como o Batalhão de Operaçóes Policiais Especiais (BOPE) e a CORE em detrimento de batalhóes de área; aumento das motivaçóes de mandado de busca e apreensão e diminuição das de repressão ao tráfico de drogas e armas; e, finalmente, aumento da razão entre o número de operaçóes policiais e o de mortos/feridos e redução da razão entre o número de operaçôes e prisóes e apreensóes. No seu conjunto, essas características apontam uma maior especialização dos grupamentos que realizam as operaçóes, como também uma interface maior com o poder judicial. Entretanto, em que pese a diminuição muito significativa do volume total de mortos, feridos, prisóes e apreensóes, as operaçóes policiais tendem a apresentar uma probabilidade maior da ocorrência de mortos e feridos e menor de prisões e apreensões quando feitas as suas razóes. Estas características são importantes elementos a serem analisados em estudo específico, com vistas ao aperfeiçoamento dos mecanismos de contenção dos efeitos de violência e da eficiência policial para proposiçóes futuras. 


\section{REFERÊNCIAS}

ALMEIDA, Silvio Luiz de. O que é racismo estrutural? Belo Horizonte: Letramento, 2018.

BRUNO, Isabelle; DIDIER, Emmanuel; PRÉVIEUX, Julien. Statactivisme: comment lutter avec les nombres. Paris: La Découverte, 2014.

CERQUEIRA, Daniel; COELHO, Danilo Santa Cruz. Democracia racial e homicídios de jovens negros na cidade partida. Brasília: Ipea, 2017. (Textos para Discussão, n. 2267).

FBSP - FÓRUM BRASILEIRO DE SEGURANÇA PÚBLICA. Anuário brasileiro de segurança pública: 2019. [s.l.]: FBSP, 2019. Disponível em: <https://forumseguranca.org.br/publicacoes_ posts/13-anuario-brasileiro-de-seguranca-publica/>.

HIRATA, Daniel; GRILLO, Carolina. Operaçóes policiais no Rio de Janeiro. Rio de Janeiro: Fundação Heinrich Böll, 2019. Disponível em: <https://br.boell.org/pt-br/2019/12/21/operacoespoliciais-no-rio-de-janeiro>.

HIRATA, Daniel; GRILLO, Carolina; DIRK, Renato. Operaçôes policiais e ocorrências criminais: por um debate público qualificado. Dilemas: Revista de Estudos de Conflito e Controle Social, Rio de Janeiro, p. 1-19, 2020. Disponível em: <https://www.reflexpandemia.org/texto-57>.

LASCOUMES, Pierre; LE GALÈS, Patrick. Gouverner par les instruments. Paris: Presses de Sciences Po, 2004.

MONTEIRO, Joana; FAGUNDES, Eduardo; GUERRA, Julia. Letalidade policial e criminalidade violenta. Revista de Administraçáo Pública, Rio de Janeiro, v. 54, n. 6, nov./dez. 2020.

RAMOS, Silvia et al. Racismo, motor da violência: um ano da Rede de Observatórios da Segurança. Rio de Janeiro: CESeC, jul. 2020. Disponível em: <https://cesecseguranca.com.br/livro/racismomotor-da-violencia-um-ano-da-rede-de-observatorios-da-seguranca/ $>$.

REDES DE DESENVOLVIMENTO DA MARÉ. Boletim direito à segurança pública na Maré: 2016. Rio de Janeiro: Redes da Maré, 2017. Disponível em: <https://www.redesdamare.org.br/ media/downloads/arquivos/BoletimSegPublica.pdf>.

Boletim direito à segurança pública na Maré: 2017. Rio de Janeiro: Redes da Maré, 2018. Disponível em: <https:/www.redesdamare.org.br/media/downloads/arquivos/BoletimSegPublica_2017.pdf>.

Boletim direito à segurança pública na Maré: 2018. Rio de Janeiro: Redes da Maré, 2019. Disponível em: <https://www.redesdamare.org.br/media/downloads/arquivos/BoletimSegPublica2018. final.pdf>.

. Boletim direito à segurança pública na maré: 2019. Rio de Janeiro: Redes da Maré, 2020. Disponível em: <https://www.redesdamare.org.br/media/downloads/arquivos/BoletimSegPublica_ EdicaoEspeci.pdf>. 